\title{
A technique to capture multi-disciplinary tacit knowledge during the conceptual design phase of a building project
}

\begin{abstract}
The construction industry is suffering from incomplete knowledge flow that results in time and cost over-runs. Many researchers believe that a large part of this problem is related to the design phase being a tacit knowledge-dominated area. Since tacitness of knowledge contributes to incomplete flow of knowledge, we posit that facilitating the conversion of tacit knowledge to explicit knowledge can improve the overall knowledge flow. Within this context, this paper analyses recognised knowledge-capturing techniques and compares them in view of the operating characteristics of the conceptual design phase. This paper proposes a new tacit knowledge-capturing technique for this phase. The outcomes include a new knowledge-capturing technique, a method for validation of the proposed technique, and recommendations on how to deal with the challenges concomitant with the application and utilisation of the proposed technique in the building industry. By proposing a combinational tacit knowledge-capturing technique, this study attempts to mitigate the impact of the potential incomplete knowledge flow during the conceptual design phase in building projects.
\end{abstract}

Keyword: Knowledge management process; Dynamic knowledge flows; Knowledgecapturing techniques; Tacit knowledge conversion 